СОСТОЯНИЕ СОСНОВО-БЕРЕЗОВЫХ ПОЛЕЗАЩИТНЫХ

ЛЕСНЫХ ПОЛОС В УСЛОВИЯХ РАДИОАКТИВНОГО ЗАГРЯЗНЕНИЯ БРЯНСКОЙ ОБЛАСТИ

Вечеров В.В., Маркина 3.Н.

ФГБОУ ВО «Брянский государственный инженерно-технологический университет», Брянск, e-mail: mail@bgita.ru

\begin{abstract}
Приведен анализ роста и состояния сосново-березовых полезащитных лесных полос на дерново-подзолистых почвах в условиях радиоактивного загрязнения Брянской области. Учитывались следующие характеристики полезащитных лесных полос: возраст, схема смешения древесных пород, схема размещения растений в рядах и ширина междурядий, густота посадки при создании древостоя, средний диаметр и средняя высота насаждения, класс бонитета и тип лесорастительных условий (ТЛУ), запас древостоя. Показаны почвообразующие породы, определяющие лучший рост сосново-березовых древостоев и оценено содержание в них физической глины. Влияние почвообразующих пород на рост древесных пород определяется их гранулометрическим, минералогическим и химическим составом на основании сопоставления лесорастительных свойств почв с таксационными показателями древостоев полезащитных лесных полос. Лучшие условия роста вне зависимости от возраста для сосново-березовых 4-рядных полезащитных лесных полос создаются на легких почвах, сформировавшихся на водно-ледниковых почвообразующих породах с оптимальной густотой посадки 4440 шт./га (схема размещения $3 \times 0,75)$. Плотность загрязнения ${ }^{137} \mathrm{Cs}$ в полезащитных лесных полосах составляет $12,6-105,7 \mathrm{Ku} / \mathrm{\kappa м}^{2}$. Существующие уровни загрязнения не оказывают влияния на рост древесных насаждений полезащитных лесных полос независимо от их состава.
\end{abstract}

Ключевые слова: полезащитные лесные полосы, дерново-подзолистые почвы, радиоактивное загрязнение

\title{
CONDITION OF PINE-BIRCH SHELTER BELTS UNDER RADIOACTIVE CONTAMINATION IN BRYANSK REGION
}

\author{
Vecherov V.V., Markina Z.N.
}

Bryansk State Engineering and Technological University, Bryansk,e-mail: mail@bgita.ru

\begin{abstract}
The analysis of the growth and status of pine and birch shelter belts on sod-podzolic soils in conditions of radioactive contamination. We consider the following characteristics of shelter belts: age, circuit mixing trees, plant layout in rows and row spacing, planting density to create the stand, the average diameter and the average height of plantings, yield class and type of forest conditions (TLC), growing stock. Established types of soils under pine and birch forest belts, evaluated the content of physical clay in the parent rock. Influence of parent rocks on the growth of trees is determined by their size distribution, mineralogical and chemical composition on the basis of comparison of the silvicultural properties of soils inventory indices stands shelter belts. The best conditions for growth, regardless of age for pine and birch 4-row shelterbelt forest strips are created on loam soils formed on fluvioglacial parent material with the optimum planting density $4440 \mathrm{pcs}$. /ga (layout $3 \times 0,75$ ). ${ }^{137} \mathrm{Cs}$ contamination density in shelter belts is $12,6-105,7 \mathrm{Ku} / \mathrm{km}^{2}$. The existing levels of contamination do not affect the growth of tree plantation of shelter belts, regardless of their composition.
\end{abstract}

Keywords: shelter belts, sod-podzolic soils, radioactive contamination

Радиоэкологическое состояние почвенного покрова наиболее загрязнённых югозападных районов Брянской области до настоящего времени остаётся нестабильным, сложным, и коренных изменений в сторону улучшения ещё не наступило [4, 5, 8]. Несмотря на то, что с момента аварии на Чернобыльской АЭС прошло 30 лет, проблема радиоактивного загрязнения территории не утратила своей важности. В связи с этим особую актуальность приобретает решение вопросов, связанных с разработкой и внедрением действенного механизма реабилитации территорий $[1,2,3]$. Большой практический интерес представляют исследования возможности лесоразведения полезащитных лесных полос на территориях с повышенным содержанием радиоактивных ве- ществ. Формирование лесных насаждений путем чередования полезащитных лесных полос различного породного состава с незалесёнными участками в зонах с высоким уровнем радиоактивного загрязнения позволит снизить распространение радионуклидов в окружающей среде $[6,8]$.

Цель исследования - изучение и анализ состояния сосново-березовых полезащитных лесных полос и разработка предложений по полезащитному лесоразведению в условиях радиоактивного загрязнения юго-запада Брянской области.

\section{Материалы и методы исследований}

Объектами исследований являлись смешанные сосново-березовые насаждения полезащитных лесных полос (ПЛП), загрязненные ${ }^{137} \mathrm{Cs}$, расположенные на территории ГКУ Брянской области «Клинцовское 
лесничество» и «Злынковское лесничество». Плотность загрязнения (ПЗ) на пробных площадях изменяется от 12,6 Кu/км² (ПП 5) до 105,7 Кu/км² (ПП 17). Сосново-березовые насаждения ПЛП произрастают на дерново-подзолистых почвах, сформировавшихся на различных почвообразующих породах, в типе лесорастительных условий свежей и свежей сложной субори. Временные пробные площади закладывали по общепринятым методикам в соответствии с ГОСТ 16128-70 «Площади пробные лесоустроительные (метод закладки)» и ОСТ 56-69-83 «Площади пробные лесоустроительные. Метод закладки». На основании данных измерительной таксации рассчитывали таксационные характеристики древостоев (средний диаметр, высота, относительная полнота, запас). На каждой пробной площади закладывали почвенный разрез глубиной 1,5-2,0 м. Изучение морфологических свойств почвы выполняли в соответствии с ОСТ 56-81-84 «Полевые исследования почвы». В почвенных образцах определяли гранулометрический состав по Н.А. Качинскому, физико-химические свойства почв выполняли методами, принятыми в лесо- и агрослужбах РФ. Определение удельной активности ${ }^{137} \mathrm{Cs}$ выполняли гамма-спектрометрическим методом на УСК «Гамма-Плюс».

\section{Результаты исследований и их обсуждение}

Территория района проведения исследований представляет собой слабоволнистую равнину с пологими склонами, в юго-западной части которой сформировались дерново-подзолистые почвы легкого гранулометрического состава разной степени оподзоленности и оглеенности на водно-ледниковых и моренных отложениях. Почвы обладают низким естественным плодородием, бедны подвижными формами элементов минерального питания, органическим веществом, имеют сильнокислую и кислую реакцию почвенной среды. Содержание физической глины в супесчаных почвах не превышает $10-20 \%$, в легкосуглинистых - 20-30\%. Плотность загрязнения ${ }^{137} \mathrm{Cs}$ в полезащитных лесных полосах составляет 12,6-105,7 Ku/км².

Детальное изучение почвенно-экологических условий в полезащитных лесных полосах показало, что в условиях радиоактивно загрязненных юго-западных районов области древесные породы имеют некоторые различия в росте на разных почвообразующих породах. В лесополосах с сосново-березовыми древостоями (табл. 1) в возрасте 73 лет рост сосны обыкновенной (Pinus sylvestris L.) по диаметру на $17,0-22,2 \%$ и березы повислой (Betula pendula Roth.) на 36,3-57,0\% больше на легкосуглинистой почве, сформировавшейся на покровном суглинке (ПП 8), чем на легкосуглинистой почве на моренных отложениях, перекрытых покровным суглинком (ПП 2, ПП 4), и на 12,2 и 7,1-13,0\% по высоте соответственно.
Результаты проведенных исследований показывают, что сосново-березовые древостои на пробных площадях являются высокопродуктивными, произрастают по I (ПП 5, $17,18)$ и II (ПП $2,3,8)$ классам бонитета (табл. 1). Запас изменяется от 151 (ПП 17) до $226 \mathrm{~m}^{3} /$ га (ПП 18). Основными показателями, влияющими на запас насаждений, являются относительная полнота древостоев, доля березы в составе насаждения, свойства почвообразующих пород, а наименьший запас имеет древостой с наибольшей долей березы (ПП 17 - 8Б2С). Наиболее продуктивны древостои полезащитных лесных полос (ПП 18) в типе лесорастительных условий свежая сложная суборь $\left(\mathrm{C}_{2}\right)$, где отмечен наибольший запас насаждений, который на $17,1 \%$ больше, чем в свежей субори $\left(\mathrm{B}_{2}\right)$. В сосново-берёзовых насаждениях условия для роста и развития сосны обыкновенной благоприятные, что связано с вовлечением в биологический круговорот веществ опада берёзы, богатого основаниями, и улучшением лесорастительных свойств почв [9].

В возрасте 73 лет (ПП 2, ПП 4, ПП 8) при одинаковой густоте посадки в условиях свежей субори лучшие показатели роста сосны обыкновенной выявлены на почве, сформировавшейся на покровном суглинке (ПП 8). Разница в сравниваемых полосах при одинаковой густоте создания составила по диаметру 18,0-23,3\%, запасу по сосне $-8,6-36,4 \%$ и практически одинаковая по высоте. Рост березы повислой больше по высоте на 7,1-13\% и на $36,3-57,0 \%$ по диаметру. Это связано с полнотой насаждений, их сохранностью, особенностями роста и свойствами почвообразующих пород. Сравнение влияния густоты посадки на рост сосны обыкновенной в 4-рядных полосах показало снижение роста сосны при увеличении густоты создания (ПП 18) по диаметру на $17,2 \%$ и практически одинаковые показатели по высоте, но по запасу наблюдается превышение при большей густоте $(14,9 \%)$.

Исследование запасов элементов питания в почвах полезащитных лесных полос показало (табл. 1), что обеспеченность сосново-березовых насаждений фосфором и калием высокая. Из всех элементов питания древесные породы в наибольшем количестве потребляют азот, степень снабжения которым определяет их продуктивность. Потребность насаждения в элементах минерального питания определяется в основном их выносом из почвы. Сопоставив вынос химических элементов растениями 
Таблица 1

Характеристика сосново-березовых полезащитных лесных полос

\begin{tabular}{|c|c|c|c|c|c|c|c|}
\hline \multirow{2}{*}{\multicolumn{2}{|c|}{ Показатели }} & \multicolumn{6}{|c|}{ Пробные площади и номера разрезов } \\
\hline & & $2^{*}$ & 4 & 8 & 5 & 18 & 17 \\
\hline \multicolumn{2}{|l|}{$\frac{\text { Состав }}{\text { Возраст, лет }}$} & $\frac{8 \mathrm{C} 2 \mathrm{~b}}{73}$ & $\frac{7 \mathrm{C} 3 \mathrm{5}}{73}$ & $\frac{9 \mathrm{C} 15}{73}$ & $\frac{5 \mathrm{C} 5 \mathrm{~b}}{51}$ & $\frac{7 \mathrm{C} 3 \mathrm{~B}}{50}$ & $\frac{8 \mathrm{Б} 2 \mathrm{C}}{59}$ \\
\hline \multicolumn{2}{|l|}{ Схема смешения } & \multicolumn{4}{|c|}{ 1pБ2pC1pБ } & \multicolumn{2}{|c|}{$1 \mathrm{p} Б 1 \mathrm{pC} 1 \mathrm{p} Б$} \\
\hline \multicolumn{2}{|l|}{$\begin{array}{l}\text { Схема размещения } \\
\text { Густота посадки шт./га }\end{array}$} & $\frac{3 \times 0,75}{4440}$ & $\frac{3 \times 0,75}{4440}$ & $\frac{3 \times 0,75}{4440}$ & $\frac{3 \times 0,75}{4440}$ & $\frac{3 \times 0,5}{6670}$ & $\frac{2,5 \times 1,0}{4000}$ \\
\hline \multicolumn{2}{|l|}{ Средняя высота, м; $\frac{\mathrm{C}}{\mathrm{b}}$} & $\frac{20,9}{14,6}$ & $\frac{19,0}{15,4}$ & $\frac{20,2}{16,5}$ & $\frac{18,9}{19,4}$ & $\frac{19,1}{17,6}$ & $\frac{18,2}{18,3}$ \\
\hline \multicolumn{2}{|l|}{ Средний диаметр, см; $\frac{\mathrm{C}}{\mathrm{b}}$} & $\frac{27,0}{19,0}$ & $\frac{28,2}{16,5}$ & $\frac{33,3}{25,9}$ & $\frac{29,3}{28,0}$ & $\frac{22,6}{20,8}$ & $\frac{21,8}{20,8}$ \\
\hline \multicolumn{2}{|l|}{$\frac{\text { Класс бонитета }}{\text { ТЛУ }}$} & $\frac{\mathrm{II}}{\mathrm{B}_{2}}$ & $\frac{\mathrm{II}}{\mathrm{B}_{2}}$ & $\frac{\mathrm{II}}{\mathrm{B}_{2}}$ & $\frac{\mathrm{I}}{\mathrm{B}_{2}}$ & $\frac{\mathrm{I}}{\mathrm{C}_{2}}$ & $\frac{\mathrm{I}}{\mathrm{C}_{2}}$ \\
\hline \multicolumn{2}{|l|}{ Запас, м³/га; $\frac{\mathrm{C}}{\mathrm{b}}$} & $\frac{162}{28}$ & $\frac{129}{45}$ & $\frac{176}{17}$ & $\frac{100}{87}$ & $\frac{170}{56}$ & $\frac{124}{33}$ \\
\hline \multicolumn{2}{|l|}{ Относительная полнота $\frac{\mathrm{C}}{\mathrm{b}}$} & $\frac{0,5}{0,2}$ & $\frac{0,4}{0,3}$ & $\frac{0,5}{0,1}$ & $\frac{0,3}{0,4}$ & $\frac{0,5}{0,3}$ & $\frac{0,6}{0,1}$ \\
\hline \multicolumn{2}{|c|}{ Плотность загрязнения ${ }^{137} \mathrm{Cs}, \mathrm{Ku} / \mathrm{KM}^{2}$} & 24,4 & 19,3 & 21,9 & 12,6 & 92,6 & 105,7 \\
\hline \multirow[t]{3}{*}{$\begin{array}{l}\text { Запас к метровому слою, кг/га } \\
\text { Вынос кг/га в год }\end{array}$} & $\mathrm{N}$ & $\frac{25,4}{38,4}$ & $\frac{44,6}{40,6}$ & $\frac{35,5}{38,4}$ & $\frac{12,0}{41,0}$ & $\frac{33,8}{40,8}$ & $\frac{43,3}{41,0}$ \\
\hline & $\mathrm{P}_{2} \mathrm{O}_{5}$ & $\frac{1531}{4,3}$ & $\frac{1906}{4,9}$ & $\frac{1079}{4,3}$ & $\frac{1537}{16,9}$ & $\frac{227}{4,9}$ & $\frac{270}{4,8}$ \\
\hline & $\mathrm{K}_{2} \mathrm{O}$ & $\frac{1260}{15,3}$ & $\frac{570}{4,7}$ & $\frac{1000}{15,3}$ & $\frac{1073}{16,5}$ & $\frac{293}{17,0}$ & $\frac{358}{16,9}$ \\
\hline \multicolumn{2}{|l|}{$\mathrm{pH}$} & 3,9 & 4,0 & 4,9 & 3,9 & 4,0 & 3,9 \\
\hline \multicolumn{2}{|l|}{ Содержание гумуса, \% } & 1,80 & 4,87 & 4,15 & 0,99 & 1,81 & 1,98 \\
\hline \multicolumn{2}{|l|}{ Физическая глина, гор., \% $\frac{\mathrm{A}_{1}}{\mathrm{C}^{1}}$} & $\frac{21,6}{10,9}$ & $\frac{28,5}{10,5}$ & $\frac{27,4}{20,4}$ & $\frac{29,8}{19,2}$ & $\frac{18,1}{10,1}$ & $\frac{23,4}{20,0}$ \\
\hline
\end{tabular}

* П р и м еч а н и е. 2 - смесь моренных и водно-ледниковых отложений; 4, 5 - моренные отложения, перекрытые покровным суглинком; 8 - покровный суглинок; 17, 18 - моренные отложения.

из почвы и запасы их в корнеобитаемом слое, можно оценить лесорастительные свойства почв. Вынос азота сосной обыкновенной превышает его запас в почве, но, как отмечает Л.Б. Холопова [9], при содержании легкогидролизуемого азота в почве 12 кг/га и более обеспеченность азотом высокая. Степень обеспеченности древостоев азотом определяет их продуктивность, что подтверждается I и II классами бонитета. Максимальное потребление азота древесными породами наблюдается в возрасте 50-59 лет и составляет 40,641,0 кг/га в год. Нашими исследованиями выявлено, что лучший рост сосны в полезащитных лесных полосах отмечается при содержании физической глины 19,2-20,4\% в почвообразующей породе. Как отмечает С.А. Родин, лучшие условия для роста сосны при содержании физической глины в почвенном профиле $20-25 \%$ [7].
Влияние почвенно-экологических условий на биометрические показатели сосны обыкновенной на различных почвообразующих породах определялось методом статистического анализа (табл. 2).

Сравнивая вариационные ряды распределения по диаметру на уровне груди и по высоте, можно предположить, что имеются существенные различия в их росте. Анализ распределения диаметров и высот древостоев на пробных площадях выявил, что вариабельность диаметра находится в пределах от 20,9 см до 31,8 см; вариабельность высоты - в пределах от 17,4 до 19,2 м. Высокая изменчивость $(C=21-40 \%)$ характерна для диаметров всех сосново-березовых насаждений вне зависимости от почвообразующих пород, для высоты - на почвах, сформировавшихся на смеси моренных и водно-ледниковых отложений (ПП 2). Низкая вариабельность отмечена на 
ПП 5, 17, 18, что связано с возрастом насаждений (49-59 лет). Распределение деревьев по диаметру имеет небольшую положительную асимметрию и отрицательный эксцесс на всех пробных площадях. Отрицательное значение эксцесса свидетельствует о неравномерном распределении стволов по ступеням толщины, что можно увязать с влиянием почвенно-экологических условий.
Разница показателей среднего арифметического и истинного среднего диаметра так же свидетельствует о статистической неоднородности древостоя.

Проверка достоверности эффективности почвенно-экологических условий на рост сосны обыкновенной в полезащитных насаждениях в условиях радиоактивного загрязнения проводилась по критерию Стьюдента.

Результаты статистического анализа

Таблица 2 основных биометрических показателей сосново-березовых насаждений

\begin{tabular}{|c|c|c|c|c|c|c|c|c|c|}
\hline \multirow{2}{*}{ ПП } & \multirow{2}{*}{$\begin{array}{c}\text { Кол-во } \\
\text { изм. }\end{array}$} & \multicolumn{8}{|c|}{ Статистические характеристики } \\
\hline & & $\sigma_{x}, \mathrm{~cm}$ & $\pm m_{\sigma}, \mathrm{cM}$ & $M_{x}, \mathrm{~cm}$ & $\pm m_{M x}, \mathrm{cM}$ & $C_{x}, \%$ & $P_{x}, \%$ & As & $E$ \\
\hline \multicolumn{10}{|c|}{ Диаметр, см } \\
\hline 2 & 307 & 7,66 & 0,33 & 24,3 & 0,59 & 31,5 & 1,9 & 0,34 & $-0,39$ \\
\hline 4 & 305 & 8,07 & 0,40 & 29,3 & 0,57 & 27,5 & 1,9 & 0,16 & $-0,13$ \\
\hline 5 & 301 & 6,88 & 0,34 & 28,1 & 0,48 & 24,4 & 1,7 & 0,06 & $-0,10$ \\
\hline 8 & 327 & 7,00 & 0,33 & 31,8 & 0,49 & 22,0 & 1,5 & 0,38 & $-0,39$ \\
\hline 17 & 313 & 6,15 & 0,30 & 20,9 & 0,42 & 29,5 & 2,0 & 0,23 & $-0,87$ \\
\hline 18 & 301 & 5,89 & 0,24 & 21,2 & 0,34 & 27,7 & 1,6 & 0,15 & $-0,94$ \\
\hline \multicolumn{10}{|c|}{ Высота, м } \\
\hline 2 & 60 & 3,65 & 0,33 & 17,4 & 0,47 & 21,0 & 2,7 & 0,16 & $-1,42$ \\
\hline 4 & 46 & 3,49 & 0,36 & 18,6 & 0,51 & 18,8 & 2,8 & $-0,53$ & $-0,40$ \\
\hline 5 & 47 & 1,64 & 0,17 & 18,7 & 0,24 & 8,8 & 1,3 & $-0,76$ & 0,32 \\
\hline 8 & 46 & 2,35 & 0,24 & 19,2 & 0,35 & 12,2 & 1,8 & $-0,29$ & $-1,10$ \\
\hline 17 & 43 & 1,81 & 0,19 & 17,8 & 0,28 & 10,1 & 1,6 & $-0,31$ & $-0,36$ \\
\hline 18 & 45 & 1,92 & 0,20 & 18,2 & 0,29 & 10,6 & 1,6 & $-0,01$ & $-0,36$ \\
\hline \multicolumn{10}{|c|}{ Запас, м³/га } \\
\hline $\mathrm{Cp}$ & 6 & 36,8 & 9,2 & 199,8 & 13,0 & 18,4 & 6,5 & 1,70 & 3,92 \\
\hline
\end{tabular}

* П р и м е ч а н и е. $\sigma_{\mathrm{x}} \pm m_{\sigma}-$ основное (стандартное) отклонение с основной ошибкой; $M_{x} \pm m_{M x}-$ среднеарифметическая величина с основной ошибкой; $C_{x}-$ коэффициент изменчивости; $P_{x}-$ точностьиопыта; As и $E$ - асимметрия и эксцесс.

Таблица 3

Результаты сравнительного анализа влияния почвенно-экологических условий на биометрические показатели сосны обыкновенной полезащитных лесных полос

\begin{tabular}{|c|c|c|c|c|c|c|c|c|c|c|}
\hline \multirow[b]{2}{*}{ ПП } & \multicolumn{5}{|c|}{ Диаметр на высоте груди, см } & \multicolumn{5}{|c|}{ Высота, м } \\
\hline & $M_{x} \pm m_{M x}$ & $\sigma_{x} \pm m_{\sigma \mathrm{x}}$ & $C_{x}, \%$ & $P_{0 \%}$, & $\begin{array}{c}\text { Коэффи- } \\
\text { циент су- } \\
\text { щество- } \\
\text { вания } \\
\text { различия }\end{array}$ & $M_{x} \pm m_{M x}$ & $\sigma_{\mathrm{x}} \pm m_{\sigma \mathrm{x}}$ & $\underset{0 \%}{C}$, & $\underset{0 \%}{P}$, & \begin{tabular}{|c|} 
Коэффи- \\
циент су- \\
щество- \\
вания \\
различия
\end{tabular} \\
\hline 8 & $31,8 \pm 0,49$ & $7,00 \pm 0,33$ & 22,04 & 1,46 & 9,78 & $19,2 \pm 0,35$ & $2,35 \pm 0,24$ & 12,2 & 1,8 & 3,07 \\
\hline 2 & $24,3 \pm 0,59$ & $7,66 \pm 0,33$ & 31,52 & 1,89 & & $17,4 \pm 0,47$ & $3,65 \pm 0,33$ & 21,0 & 2,7 & \\
\hline 8 & $31,8 \pm 0,49$ & $7,00 \pm 0,33$ & 22,04 & 1,46 & 3,33 & $19,2 \pm 0,35$ & $2,35 \pm 0,24$ & 12,2 & 1,8 & 0,97 \\
\hline 4 & $29,3 \pm 0,57$ & $8,07 \pm 0,40$ & 27,51 & 1,94 & & $18,6 \pm 0,51$ & $3,49 \pm 0,36$ & 18,8 & 2,8 & \\
\hline 5 & $28,1 \pm 0,48$ & $6,88 \pm 0,34$ & 24,44 & 1,71 & 11,73 & $18,7 \pm 0,24$ & $1,64 \pm 0,17$ & 8,8 & 1,3 & 1,33 \\
\hline 18 & $21,2 \pm 0,34$ & $5,89 \pm 0,24$ & 27,74 & 1,60 & & $18,2 \pm 0,29$ & $1,92 \pm 0,20$ & 10,6 & 1,6 & \\
\hline 5 & $28,1 \pm 0,48$ & $6,88 \pm 0,34$ & 24,44 & 1,71 & 11,29 & $18,7 \pm 0,24$ & $1,64 \pm 0,17$ & 8,8 & 1,3 & 2,44 \\
\hline 17 & $20,9 \pm 0,42$ & $6,15 \pm 0,30$ & 29,49 & 2,02 & & $17,8 \pm 0,28$ & $1,81 \pm 0,19$ & 10,1 & 1,6 & \\
\hline
\end{tabular}


Результаты проведенных исследований (табл. 3) показывают, что сравнение показателей диаметра и высоты сосны, произрастающей на покровном суглинке и на морене, перекрытой покровным суглинком, различия существенны (ПП 8 и ПП 2; $t_{d}=9,78>t_{0,05}=1,96 ; \quad t_{h}=3,07>t_{0,05}=1,98 ;$ ПП 8 и ${ }^{0,05}$ ПП 4; $\quad\left(t_{d}^{h}=3,33>t_{0,05}^{0,05}=1,96\right.$; $\left.t_{h}=0,97>t_{0,05}=1,99\right)$ для 73-летних насаждений. При сравнении 50-59-летних древостоев сосны более сильное влияние проявляется при произрастании сосны на морене, перекрытой покровным суглинком, чем на одной морене (ПП 5 и ПП 18; $t_{d}=11,73>t_{0.05}=1,96 ; t_{h}=1,33>t_{0,05}=1,99$; ПІП 5 и ППП 17; $t_{d}=11,29>t_{0,05}^{0,05}=1,96$; $\left.t_{h}=2,44>t_{0,05}=1,99\right) . \quad$ Результаты свидетельствуют о том, что биометрические показатели сосны обыкновенной в условиях радиоактивного загрязнения напрямую зависят от лесорастительных свойств почв и почвообразующих пород.

Обработка результатов исследований влияния почвенно-экологических условий на биометрические показатели древесных пород, выполненная методом регрессионного анализа (табл. 4), позволила установить тесные регрессионно-корреляционные связи между ними. Установлена весьма высокая (по Чеддоку) тесная связь между биометрическими показателями (средним диаметром и средней высотой) и физикохимическими свойствами дерново-подзолистых почв. Коэффициенты множественной корреляции моделей составили от 0,91 до 0,99 ( $F=14,32-99,65$, при $P<0,05)$.

Коэффициенты корреляции $(R)$ и детерминации $\left(R^{2}\right)$ по моделям оказались близки к 1. Это указывает на то, что почти вся изменчивость средних диаметров и высот объясняется вариацией факторных почвенных признаков. Стандартные ошибки определения этих величин значительно ниже точности его нахождения.

Судя по коэффициенту детерминации $\left(R^{2}\right)$ для всех изучаемых почвенных слоев 0,93-0,99\% изменений среднего диаметра и 0,94-0,98\% средней высоты обусловлены содержанием основных элементов питания и физической глины.

Таким образом, биометрические показатели древесных пород полезащитных лесных полос находятся в прямой зависимости от уровня почвенного плодородия.

\section{Выводы}

1. В сосново-березовых полезащитных лесных полосах лучшие условия для роста сосны обыкновенной и березы повислой отмечены на почвах, сформировавшихся на покровном суглинке, по сравнению с почвами на моренных отложениях, перекрытых покровным суглинком, что подтверждается I и II классами бонитета. Различия составляют по диаметру 17,0-22,2\% для сосны и 36,3-57,0\% для березы, по высоте $-12,2 \%$ и 7,1-13,0\% соответственно.

2. Сосново-березовые древостои в 3и 4-рядных полезащитных лесных полосах лучше произрастают на супесчано-суглинистых почвах с оптимальной густотой посадки 4440 шт./га, схемой смешения $3 \times 0,75$ м в типе лесорастительных условий является свежая суборь $\left(\mathrm{B}_{2}\right)$ и свежая сложная суборь $\left(\mathrm{C}_{2}\right)$, что подтверждается наибольшим запасом в сосново-березо-

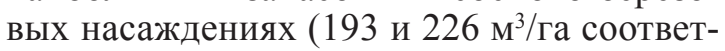
ственно) и I-II классами бонитета.

Таблица 4

Зависимость биометрических показателей полезащитных лесных полос от лесорастительных свойств дерново-подзолистых почв (слой 0-50 см)

\begin{tabular}{|c|c|c|c|c|}
\hline Уравнение множественной регрессии & $R$ & $R^{2}$ & $\begin{array}{c}F, \text { при } \\
\mathrm{p}<0,05\end{array}$ & $\begin{array}{l}\text { Стандартная } \\
\text { ошибка }\end{array}$ \\
\hline \multicolumn{5}{|c|}{ Сосна обыкновенная } \\
\hline $\begin{array}{l}D=1,2084 \cdot g l+3,7765 \cdot H u m+0,0173 \cdot \mathrm{P}_{2} \mathrm{O}_{5}-0,0220 \cdot \mathrm{K}_{2} \mathrm{O} \\
H=0,8052 \cdot g l+4,1746 \cdot H u m+0,0116 \cdot \mathrm{P}_{2} \mathrm{O}_{5}-0,0155 \cdot \mathrm{K}_{2} \mathrm{O}\end{array}$ & $\begin{array}{l}0,98 \\
0,97\end{array}$ & $\begin{array}{l}0,96 \\
0,95\end{array}$ & $\begin{array}{l}66,05 \\
51,13\end{array}$ & $\begin{array}{l}6,36 \\
5,17\end{array}$ \\
\hline \multicolumn{5}{|l|}{ Береза повислая } \\
\hline $\begin{array}{l}D=1,3787 \cdot g l+3,6076 \cdot H u m+0,0056 \cdot \mathrm{P}_{2} \mathrm{O}_{5}-0,0316 \cdot \mathrm{K}_{2} \mathrm{O} \\
H=0,8749 \cdot g l+4,0051 \cdot H u m+0,0051 \cdot \mathrm{P}_{2} \mathrm{O}_{5}-0,0204 \cdot \mathrm{K}_{2} \mathrm{O}\end{array}$ & $\begin{array}{l}0,97 \\
0,97\end{array}$ & $\begin{array}{l}0,94 \\
0,95\end{array}$ & $\begin{array}{l}33,33 \\
39,63\end{array}$ & $\begin{array}{l}7,23 \\
4,86\end{array}$ \\
\hline
\end{tabular}

* П р и м е ч а н и е: $D$ - средний диаметр, см; $H$ - средняя высота, м; $g l-\%$ содержания физической глины; Нum - \% содержания гумуса; $\mathrm{P}_{2} \mathrm{O}_{5}$ - содержание обменного фосфора; $\mathrm{K}_{2} \mathrm{O}$ - содержание обменного калия 
3. Установлена тесная связь между биометрическими показателями (средним диаметром и средней высотой) и физикохимическими свойствами дерново-подзолистых почв. Коэффициенты множественной корреляции моделей составили от 0,91 до $0,99(F=14,32-99,65$, при $P<0,05)$. Биометрические показатели древесных пород полезащитных лесных полос находятся в прямой зависимости от уровня почвенного плодородия.

4. Плотность загрязнения ${ }^{137} \mathrm{Cs}$ в полезащитных лесных полосах составляет 12,6-105,7 Ku/км². Существующие уровни загрязнения не оказывают влияния на рост древесных насаждений полезащитных лесных полос.

\section{Список литературы}

1. Алексахин Р.М., Васильев А.В., Дикарев В.Г. и др. Сельскохозяйственная радиоэкология / под ред. Р.М. Алексахина, Н.А. Корнеева. - М.: Экология, 1992. - 400 с.

2. Воробьев Г.Т. Радиоактивное загрязнение почв Брянской области: монография / Г.Т. Воробьев, Д.Е. Гучанов,
3.Н. Маркина А.А. Новиков, С.В. Карпеченко, В.С. Калацкий. - Брянск: «Грани», 1994. - 148 с.

3. Ипатьев В.А., Булко Н.И., Митин Н.В., Шабалева М.А., Диденко Л.Г. Радиоэкологический феномен лесных экосистем. - Гомель: ИЛ НАН Беларуси, 2004. - 310 с.

4. Марадудин И.И., Панфилов А.В., Шубин В.А. Основы прикладной радиоэкологии леса: уч. пособие. - М.: ВНИИЛМ, 2001. - 224 с

5. Молчанова И.В., Караваева Е.Н. Эколого-геохимические аспекты миграции радионуклидов в почвенно-растительном покрове. - Екатеринобург: УрО РАН, 2001. $-161 \mathrm{c}$

6. Прудников, П.В. Агрохимическое и агроэкологическое состояние почв Брянской области / П.В. Прудников, С.В. Карпеченко, А.А. Новиков, Н.Г. Поликарпов. - Брянск: Изд-во ГУП «Клинцовская город. тип.», 2007. -608 c.

7. Родин С.А. Повышение результативности выращивания лесных культур посадочным материалом с закрытой корневой системой / С.А. Родин, А.Р. Родин // Лесн. Вестн. 2010. - № 5. - C. 7-10.

8. Тарасенко В.П., Маркина 3.Н., Егорушкин В.А. Комплекс лесомелиоративных мероприятий по снижению негативных последствий катастрофы на Чернобыльской АЭС в зоне хвойно-широколиственных лесов / Брянск. гос. инж.технол. акад. - Брянск, 2012. - 120 с.

9. Холопова, Л.Б. Дерново-подзолистые почвы бассейна малого водотока в подмосковье // Грунтознавство. 2004. - № 1-2. - C. 16-26. 